\title{
Optical, structural and electrical characterizations of stacked Hf-based and silicon nitride dielectrics
}

\author{
L. Khomenkova a,b,c,*, P. Normand ${ }^{\text {d }}$, F. Gourbilleau ${ }^{c}$, A. Slaoui ${ }^{\text {e }}$, C. Bonafos ${ }^{b}$ \\ a $V$. Lashkaryov Institute of Semiconductor Physics of NASU, 45 Pr. Nauky, 03028 Kyiv, Ukraine \\ b CEMES/CNRS, Université de Toulouse, 29 rue J. Marvig, 31055 Toulouse Cedex 4, France \\ c CIMAP, CEA/CNRS/ENSICAEN/Unicaen, 6 Blvd Marechal Juin, 14050 Caen Cedex 4, France \\ d INN/NCSR Demokritos, 15310, Aghia Paraskevi, P.O. Box 60228, Athens, Greece \\ e ICube, 23 rue du Loess, 67037 Strasbourg, France
}

Keywords:

High-k dielectrics

RF magnetron sputtering

Plasma-enhanced chemical vapor deposition

Memory effect

\begin{abstract}
A B S T R A C T
High-k stacked dielectric structures were fabricated by a combination of RF magnetron sputtering and plasmaenhanced chemical vapor deposition. Their structural properties were studied versus deposition and annealing conditions by means of attenuated total reflection and high-resolution transmission electron microscopy techniques. All samples demonstrated smoothed surface (with a roughness below $1 \mathrm{~nm}$ ) and abrupt interfaces between the different stacked layers. No crystallization of Hf-based layers was observed after annealing at $800{ }^{\circ} \mathrm{C}$ for $30 \mathrm{~min}$, demonstrating their amorphous nature and phase stability upon annealing. Uniform capacitancevoltage characteristics were measured along the wafers for all stacks. Besides, after round-voltage sweep they demonstrate significant flat-band voltage hysteresis due to charging of the stack caused by carrier injection from the substrate. These phenomena were found to be more pronounced for the stacks with pure $\mathrm{HfO}_{2}$ layers. The stacked structures were implemented for the formation of Ge nanocrystals by means of ion implantation followed by the thermal treatment mentioned above. It was found that the spatial distribution of Ge crystallites in stacked dielectrics affects significantly their electrical properties including the trapping of charge.
\end{abstract}

\section{Introduction}

The increasing market for portable electronic products (mobile phones, digital cameras, external data storage devices, players etc.) stimulated the development of nonvolatile memory (NVM) production. Among various NVM architectures, flash memory has out run other competitors due to its full process compatibility with CMOS technology and superior performance [1]. However, conventional floating gate structures have already faced a limit due to the aggressive scaling trend in the vertical dimension.

The stacked dielectrics such as MNOS (metal-nitride-oxide-silicon), SONOS ( silicon-oxide-nitride-oxide-silicon), MONOS (metal-oxidenitride-oxide-silicon), MOHOS (metal-oxide-high-dielectric-oxidesemiconductor) etc. were considered as promising alternatives for next-generation flash memory applications due to layer's scalability, process simplicity, power economy, operation versatility, and radiation hardness [2]. Nevertheless, the continued minimization of NVM structures forces an application of high-k dielectrics instead conventional silicon nitride trapping layer. For instance, pure and/or Al-doped $\mathrm{HfO}_{2}$ layers were stacked in MONOS-like structures, demonstrating better

* Corresponding author at: V. Lashkaryov Institute of Semiconductor Physics of NASU, 45 Pr.Nauky, 03028 Kyiv, Ukraine.

E-mail address: khomen@ukr.net (L. Khomenkova). charge trapping parameters for sufficient density trap states and deep trap energy level to achieve longer retention time [3,4]. The application of stacked $\mathrm{HfO}_{2} / \mathrm{SiON} / \mathrm{SiN}$ structures as charge trap node in junction-less memory structures was demonstrated to achieve high programming speed and good endurance [5].

There are many technological approaches used for the production of high- $k$ dielectric films such as atomic layer deposition (ALD) [6,7], different chemical vapor deposition (CVD) techniques [8-10], sol-gel process $[11,12]$, pulsed laser deposition $[13,14]$ etc. However, despite its flexibility radio-frequency magnetron sputtering (RF-MS) was not often addressed $[15,16]$.

Recently we have shown the simplicity and utility of the RF-MS approach for the production of fully Hf-based NVM structures with large memory windows and enhanced dielectric properties in one deposition run [17]. Besides, we have demonstrated that this approach can be used to form Si nanocrystals (Si-ncs) in Hf-based host via phase separation process $[18,19]$ that required a lower thermal budget compared to the formation of $\mathrm{Si}$-ncs in $\mathrm{SiO}_{2}$ or $\mathrm{Al}_{2} \mathrm{O}_{3}$ matrix [20]. It was shown also that Ge-ncs can be produced in Hf-based or Zr-based dielectrics at 600$650^{\circ} \mathrm{C}$ for 30 s depending on Ge content $[21,22]$. These annealing conditions are "softer" than those used for Ge-ncs formation in $\mathrm{Si}_{3} \mathrm{~N}_{4}$ films after Ge ion implantation (800-900 ${ }^{\circ} \mathrm{C}$ for $15 \mathrm{~min}$ ) [23]

It was considered that Hf-based dielectrics suffer from their poor thermal stability as well as from the formation of a $\mathrm{SiO}_{2}$ interfacial 
layer either during the deposition process or upon thermal treatment $[24,25]$. To solve these problems, the use of silicon nitride interlayer or the doping of $\mathrm{HfO}_{2}$ with silicon were considered as the most promising [16,26].

This work concerns the elaboration of high-k dielectric structures based on the combination of Hf-based and $\mathrm{SiN}_{\mathrm{x}}$ materials grown by RF-MS and plasma-enhanced CVD (PECVD) approaches aiming at the achievement of good-quality interfaces between the various dielectric layers and smooth surface of the stacks. The interrelation of their structural and electrical properties was investigated as a function of deposition and post-annealing conditions for the pinpointing of optimal device architectures. Besides, the stacks were implanted with germanium followed by thermal treatment aiming at the formation of Ge-ncs and the investigation of their properties for possible application in memory devices.

\section{Experimental details and methods}

\subsection{Fabrication of dielectric layers and complex stacked structures}

The stacks were grown on 2-in. B-doped, (100) oriented Si wafer with a resistivity of $15 \Omega \cdot \mathrm{cm}$ (Sil'tronix S.T.). Prior deposition, Si wafer was subjected to standard RCA cleaning process, dipped in a diluted hydrofluoric solution (10\%) for $10 \mathrm{~s}$ to remove thermal $\mathrm{SiO}_{2}$ layer from the surface. This procedure allowed only hydrogen termination of the $\mathrm{Si}$ wafer surface to be reached. After drying with pure $\mathrm{N}_{2}$ flow, the wafers were immediately transferred into the "load-lock" chamber of the deposition unit.

Single $\mathrm{HfO}_{2}$ and $\mathrm{Hf}$ silicate layers were grown at $100{ }^{\circ} \mathrm{C}$ by "bottomup" RF-MS sputtering of pure $\mathrm{HfO}_{2}$ (99.9\%) and mixed $\mathrm{Si}-\mathrm{HfO}_{2}$ targets, respectively, in pure Ar plasma. To produce Hf silicate layers, pure $\mathrm{HfO}_{2}$ target was topped with calibrated Si pellets. They covered about $6 \%$ or $12 \%$ of target surface allowed to achieve $\mathrm{Hf}_{0.27} \mathrm{Si}_{0.05} \mathrm{O}_{0.68}$ or $\mathrm{Hf}_{0.17} \mathrm{Si}_{0.25} \mathrm{O}_{0.58}$ compositions, respectively. The RF power applied on $\mathrm{HfO}_{2}$ cathode was $0.74 \mathrm{~W} / \mathrm{cm}^{2}$ for all depositions.

Single Si nitride layers were produced both RF-MS and PECVD methods. In the former case, the nitride layer of the $\mathrm{SiN}_{0.8}$ composition was obtained by the sputtering of a pure Si target in $\mathrm{Ar}-\mathrm{N}_{2}$ mixed plasma at $500{ }^{\circ} \mathrm{C}$, whereas PECVD layers with $\mathrm{SiN}_{1.33}$ stoichiometry were grown from a $\mathrm{SiH}_{4}-\mathrm{N}_{2}$ mixture at $350^{\circ} \mathrm{C}$. More details about these techniques can be found in $[15,16,23]$. The deposition time for single Hf-based layers and complex stacks was chosen to achieve an equivalent oxide thickness (EOT) of in the range $2-3 \mathrm{~nm}$.

After deposition of the above dielectric films, an additional 12-nmthick Si nitride layer was grown either by RF-MS or PECVD methods. Then each wafer was cut on 2 parts. One of them was implanted with ${ }^{74} \mathrm{Ge}^{+}$ions using $\mathrm{GeH}_{4}$ gas as a source. The implantation energy and the dose were $5 \mathrm{keV}$ and $1.5 \times 10^{16} \mathrm{at} / \mathrm{cm}^{2}$, respectively. All the samples were annealed at $800^{\circ} \mathrm{C}$ for $30 \mathrm{~min}$ in a conventional horizontal furnace in pure dry nitrogen flux. The furnace was heated up to $800{ }^{\circ} \mathrm{C}$ without samples. The samples were placed on horizontal holder in cold loadlock, pumped and purged with nitrogen flow at $48 \mathrm{sccm}$ during $5 \mathrm{~min}$, and then passed in within $15 \mathrm{~s}$ into the hot zone of the furnace with continuous nitrogen flow. After annealing ( $30 \mathrm{~min}$ in the present study) the samples were removed from the furnace within $15 \mathrm{~s}$ and cooled down to room temperature in nitrogen ambient. For Ge-implanted samples such treatment allows the formation of Ge crystallites [23].

The architecture of all the samples investigated is presented in Table 1. For easier recognition of the different parts of the same wafer submitted to different treatment (annealing, implantation), the samples were re-numerated as follows. "R1" marks the as-deposited and unimplanted sample, while "R2" marks the unimplanted and annealed at $800{ }^{\circ} \mathrm{C}$ for 30 min samples. The "Ge3" mark is used for the samples submitted to $\mathrm{Ge}$ implantation and annealing at $800{ }^{\circ} \mathrm{C}$ for $30 \mathrm{~min}$.
Table 1

The parameters of the stacked structures investigated.

\begin{tabular}{|c|c|c|}
\hline $\begin{array}{l}\text { Set } \\
\text { no. }\end{array}$ & Dielectric layers (physical thickness, nm) & $\begin{array}{l}\text { Estimated EOT }{ }^{\mathrm{a}} \text { of } \\
\text { tunnel dielectric, } \\
(\mathrm{nm})\end{array}$ \\
\hline A & $12-\mathrm{nm}-\mathrm{SiN}_{1.33} / 7-\mathrm{nm}-\mathrm{HfO}_{2} / \mathrm{p}-\mathrm{Si}$ & 1.7 \\
\hline B & $12-\mathrm{nm}-\mathrm{SiN}_{1.33} / 5-\mathrm{nm}-\mathrm{HfO}_{2} / 3-\mathrm{nm}-\mathrm{SiN}_{0.8} / \mathrm{p}-\mathrm{Si}$ & 2.9 \\
\hline C & $12-\mathrm{nm}-\mathrm{SiN}_{0.8} / 5-\mathrm{nm}-\mathrm{HfO}_{2} / 3-\mathrm{nm}-\mathrm{SiN}_{0.8} / \mathrm{p}-\mathrm{Si}$ & 2.9 \\
\hline $\mathrm{D}$ & $12-\mathrm{nm}-\mathrm{SiN}_{1.33} / 6-\mathrm{nm}-\mathrm{Hf}_{0.27} \mathrm{Si}_{0.05} \mathrm{O}_{0.68} / \mathrm{p}-\mathrm{Si}$ & 1.9 \\
\hline E & $12-\mathrm{nm}-\mathrm{SiN}_{1.33} / 6-\mathrm{nm}^{-\mathrm{Hf}_{0.17}} \mathrm{Si}_{0.25} \mathrm{O}_{0.58} / \mathrm{p}-\mathrm{Si}$ & 1.9 \\
\hline $\mathrm{F}$ & 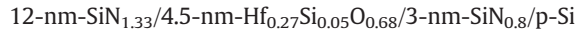 & 3.1 \\
\hline
\end{tabular}

a The EOT values for were estimated using the data for dielectric constants for Hf-based materials taken from Ref. [6,10,27]; for amorphous layers it was considered that $k_{\mathrm{HfO}_{2}}=$ $16, k_{\mathrm{HfSiO}_{\mathrm{x}}}=12$ (for Si content lower $25 \%$ ), $k_{\mathrm{SiN}_{1.33}}=7$.

\subsection{Experimental methods}

The combination of non-destructive methods allows information about microstructural and optical properties of the films. Infrared attenuated total reflectance (ATR-FTIR), was used to provide information about the structure and chemical composition of the films. The ATRFTIR spectra were measured in the range $600-4000 \mathrm{~cm}^{-1}$ by means of a $60^{\circ} \mathrm{Ge}$ Smart Ark accessory inserted in a Nicolet Nexus spectrometer.

The analysis of the structural properties was completed by highresolution transmission electron microcopy (TEM) observation. Crosssectional specimens were prepared by the standard procedure involving grinding, dimpling and $\mathrm{Ar}^{+}$ion beam thinning until electron transparency. The samples were examined using a FEI Tecnai microscope operating at $200 \mathrm{keV}$ equipped with a field emission gun and a spherical aberration corrector.

For electrical characterization, Al was deposited by thermal evaporation on the as-deposited and annealed samples to form top electrodes of $100 \times 100 \mu^{2}$ using photolithography and the back side contact. Capacitance-voltage ( $\mathrm{C}-\mathrm{V})$ characteristics of the so-formed metalinsulator-semiconductor (MIS) capacitors were measured at different frequencies using a HP 4192 A Impedance Analyzer.

\section{Results and discussion}

\subsection{ATR-FTIR spectra of as-deposited and annealed samples}

Among nondestructive methods to study thin films, ATR technique holds an important place, since it allows very thin layers to be analyzed. Unfortunately, referenced ATR data for $\mathrm{Hf}$ silicates are not so numerous. The only known data are those regarding the monoclinic $\mathrm{HfO}_{2}$ phase, while for tetragonal and cubic phases of $\mathrm{HfO}_{2}$ and, moreover, for $\mathrm{HfSiO}_{4}$ they are not available in the case of ultra-thin films.

There are few reports on traditional FTIR experiments for Hf silicate films $[26,28]$ that considered Hf silicates as a solid solution consisted of $\mathrm{HfO}_{2}$ and $\mathrm{SiO}_{2}$ unit cells, i.e. as a $\left(\mathrm{HfO}_{2}\right)_{\mathrm{x}}\left(\mathrm{SiO}_{2}\right)_{1}-\mathrm{x}$. Recently, we have shown that the interpretation of experimental ATR data for Hf silicate materials can be based on the comparison of ATR spectra obtained for amorphous $\mathrm{SiO}_{2}$ and $\mathrm{HfO}_{2}$ and their transformation due to increase of high-k material contribution [16].

The $\mathrm{SiO}_{2}$ films thicker than $50 \mathrm{~nm}$ demonstrate several vibration bands in the $600-1300 \mathrm{~cm}^{-1}$ spectral range caused by motion of oxygen atoms. They are centered at about $1076 \mathrm{~cm}^{-1}$ (transverse optical phonon, $\mathrm{TO}_{3}$ ) and $1256 \mathrm{~cm}^{-1}$ (longitude optical phonon, $\mathrm{LO}_{3}$ ), at $1160 \mathrm{~cm}^{-1}\left(\mathrm{TO}_{4}\right)$ and $1200 \mathrm{~cm}^{-1}\left(\mathrm{LO}_{4}\right)$, at $810 \mathrm{~cm}^{-1}\left(\mathrm{TO}_{2}\right)$ and $820 \mathrm{~cm}^{-1}\left(\mathrm{LO}_{2}\right)[29,30]$. The decrease of the $\mathrm{SiO}_{2}$ thickness to $10 \mathrm{~nm}$ leads to the spectral shift of all vibration bands towards the lower wavenumbers. For $\mathrm{LO}_{3}$ and $\mathrm{TO}_{3}$ it can reach about $25-30 \mathrm{~cm}^{-1}$ [31], being accompanied to the decrease of the contribution of $\mathrm{TO}_{4}-\mathrm{LO}_{4}$ phonons [30]. This transformation of FTIR spectra with the thickness scaling brings some difficulty in the recognition of different vibration bands due to their significant overlapping. Moreover, the appearance of $\mathrm{LO}_{3} \mathrm{Si}-\mathrm{O}$ 
phonon is usually reported as a signature of the formation of $\mathrm{Si} / \mathrm{SiO}_{2}$ interface [29]. Besides, the coordination number of $\mathrm{Hf}$ ions can also change versus $\mathrm{Hf}$ content in the silicate [16]. All these facts will result not only in the shift of main $\mathrm{Si}-\mathrm{O}-\mathrm{Si}$ band towards the lower wavenumbers due to the formation of Si-O-Hf bonds, but also an appearance of Hf-O vibrations themselves in $450-800 \mathrm{~cm}^{-1}$ spectral range $[15,19,28,32]$.

Usually, the simultaneous appearance of the $770-780 \mathrm{~cm}^{-1}$ and $670-680 \mathrm{~cm}^{-1}$ vibration bands in FTIR spectra of Hf-based materials is considered as a signature of monoclinic $\mathrm{HfO}_{2}$ phase [15,33], whereas the vibrations of random $\mathrm{Si}-\mathrm{O}-\mathrm{Hf}$ bonding can be seen in 900 $1020 \mathrm{~cm}^{-1}$ spectral range being centered at $\sim 970 \mathrm{~cm}^{-1}$ [34]. In the case of $\mathrm{Si}$ nitride materials the main $\mathrm{Si}-\mathrm{N}$ vibrations can be detected in the $700-1100 \mathrm{~cm}^{-1}$, demonstrating TO and LO phonons at about $840 \mathrm{~cm}^{-1}$ and $1080 \mathrm{~cm}^{-1}$ respectively [35,36].

The ATR-FTIR spectra of the as-deposited Hf-based layers and stacked structures grown by RF-MS approach are shown in Fig. 1. The pure $\mathrm{HfO}_{2}$ layer (sample A-R1) shows the presence of the characteristic $\mathrm{Hf}-\mathrm{O}$ band located at $\sim 720 \mathrm{~cm}^{-1}$. No band peaking at $770-780 \mathrm{~cm}^{-1}$ was observed that testifies to the amorphous nature of $\mathrm{HfO}_{2}$ layer. However, for this sample two vibration bands centered at $\sim 920 \mathrm{~cm}^{-1}$ and $\sim 1100 \mathrm{~cm}^{-1}$ can be seen (Fig.1a, curve 1). The former can be caused by $\mathrm{Si}-\mathrm{O}-\mathrm{Hf}$ vibrations [16] while the latter can originate either from $\mathrm{Si}-\mathrm{O}-\mathrm{Si}[16]$ or Si-O-Hf $[29,32]$ bonds. Since the deposition of $\mathrm{HfO}_{2}$ layers on Si substrate is usually accompanied by the appearance of $\mathrm{SiO}_{2}$ IL, the band at $\sim 1100 \mathrm{~cm}^{-1}$ can originate from the $\mathrm{Si}-\mathrm{O}$ bonds formed within $\mathrm{SiO}_{2}$ layer at the $\mathrm{SiO}_{2}-\mathrm{IL} / \mathrm{Si}$ interface, whereas $\mathrm{Si}-\mathrm{O}-\mathrm{Hf}$ bonds can construct at the $\mathrm{SiO}_{2}-\mathrm{IL} / \mathrm{HfO}_{2}$ interface. This assumption agrees with the data of Ref. [15].

The spectrum of the B-R1 sample demonstrates two main bands localized at about $1100 \mathrm{~cm}^{-1}$ and $750 \mathrm{~cm}^{-1}$ with a shoulder-like feature at about $880-900 \mathrm{~cm}^{-1}$ (Fig.1a, curve 2). Since the $\mathrm{SiN}_{0.8}$ layer was grown on H-terminated Si substrate, it is hardly believed that the band at about $1100 \mathrm{~cm}^{-1}$ can be caused by the formation of $\mathrm{SiO}_{2} \mathrm{IL}$. Most probably it can be attributed to the vibration of bonding groups involving $\mathrm{Si}, \mathrm{O}, \mathrm{N}$, and $\mathrm{Hf}$, which may be formed at the $\mathrm{SiN} / \mathrm{HfO}{ }_{2}$ interface in small concentration. The band peaked at $750 \mathrm{~cm}^{-1}$ originates from $\mathrm{Hf}-\mathrm{O}$ vibrations whereas the shoulder-like feature is due to overlapping of Si-N (peaking usually at $844-860 \mathrm{~cm}^{-1}$ ) and $\mathrm{Si}-\mathrm{O}-\mathrm{Hf}$ bands. The comparison of ATR spectra of the $\mathrm{SiN}_{0.8} / \mathrm{HfO}_{2}$ (sample B-R1) and the $\mathrm{SiN}_{0.8} / \mathrm{HfO}_{2} / \mathrm{SiN}_{0.8}$ structure (sample C-R1) shows that the presence of top $\mathrm{SiN}_{0.8}$ layer causes the increase of the contribution of the band peaked at $\sim 850 \mathrm{~cm}^{-1}$ (Fig.1a, curve 3).

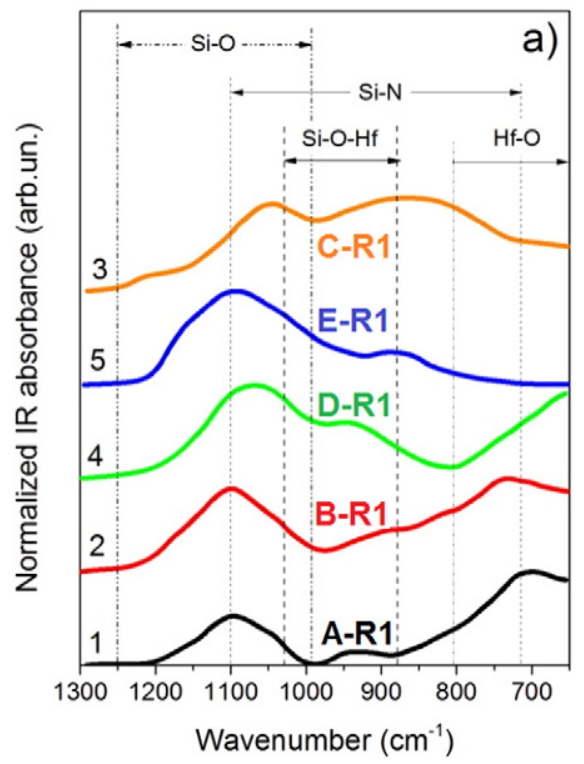

The spectra of Hf silicate layers (used in sample D-R1 (curve 4) and sample E-R1 (curve 5)) demonstrate similar vibration bands in the $900-$ $1200 \mathrm{~cm}^{-1}$ spectral range due-to Si-O-Hf bonds. However, for the film with higher Hf content (sample E-R1), the Hf-O related band is also observed in $600-850 \mathrm{~cm}^{-1}$ (curve 5 ). The featureless shape of this band is an evidence of the amorphous nature of this layer.

Annealing of the samples at $800{ }^{\circ} \mathrm{C}$ for $30 \mathrm{~min}$ in $\mathrm{N}_{2}$ flow results in the transformation of the ATR spectra (Fig. 1,b). For the samples A-R2 (curve 1), B-R2 (curve 2) and C-R2 (curve 3), the appearance of $\mathrm{LO}_{3}$ $\mathrm{Si}-\mathrm{O}$ phonon peaked at $\sim 1240 \mathrm{~cm}^{-1}$ testifies to the reconstruction of $\mathrm{Si}-\mathrm{O}$ bonds towards the configuration observed for stoichiometric $\mathrm{SiO}_{2}$ unit cell $[16,34]$. Besides, peak position of the $\mathrm{Hf}-\mathrm{O}$ band shifts towards the lower wavenumbers. No additional $\mathrm{Hf}-\mathrm{O}$ band at about $770 \mathrm{~cm}^{-1}$ was appeared that confirmed the amorphous nature of the Hf-based layer in the structures.

For the samples contained Hf silicate layers (samples D-R2 (curve 4) and E-R2 (curve 5)), annealing causes the transformation of Si-O$\mathrm{Hf}$ network via the variation of the angles and lengths of the Si-O and Hf-O bonds and does not lead to significant phase separation [16,19].

The ATR spectrum of the B-R2 sample, besides the peak at $\sim 1240 \mathrm{~cm}^{-1}$, reveals an additional peak at $\sim 1160 \mathrm{~cm}^{-1}$ (Fig.1b, curve 2 ). The appearance of these both bands can be explained by the reconstruction of $\mathrm{Si}-\mathrm{N}$ bonds $[35,36]$ as well as by the formation of $\mathrm{Si}-\mathrm{O}$ bonds. However, the location of the latter cannot be clearly distinguished from the ATR spectra.

It is worth to note also that the ATR spectrum of the sample C-R2 shows slight transformation after annealing (Fig.1b, curve 3). The contribution of the Hf-O vibrations become more pronounced in the 600$800 \mathrm{~cm}^{-1}$ spectral range, but the featureless shape of this band confirms the amorphous $\mathrm{HfO}_{2}$ nature. This means that this stacked structure is thermally stable until $800^{\circ} \mathrm{C}$ annealing. Along with this, the appearance of the peak at about $1240 \mathrm{~cm}^{-1}$ can be assigned to the $\mathrm{Si}-\mathrm{O}$ bonds similar to the case of the D-R2 sample. The shape of ATR spectrum of sample F-R1 and its transformation after annealing (sample F-R2) were found to be similar to those of sample D-R1 and D-R2, respectively. A slight higher contribution of Si-N vibration bands in the spectra for samples $\mathrm{F}$ was detected (not shown here).

\subsection{HR-TEM observation of the samples}

HR-TEM observation was performed for all the samples described above. Earlier we have demonstrated that as-deposited samples

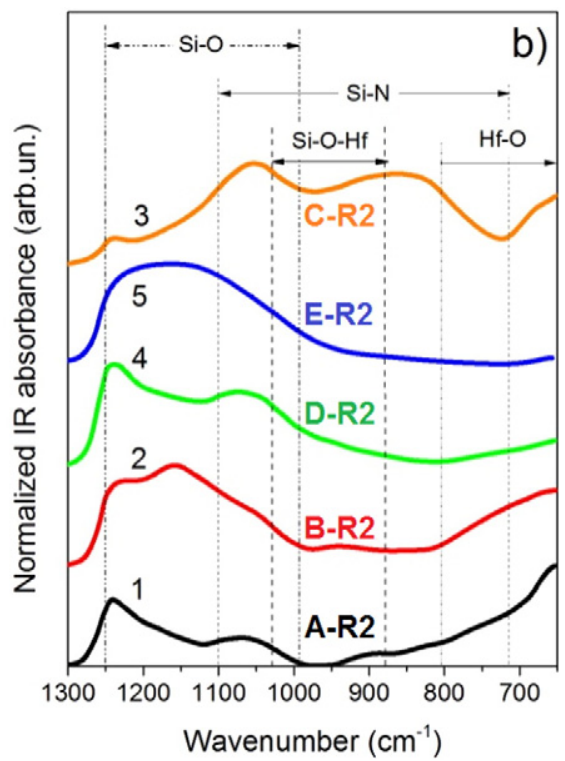

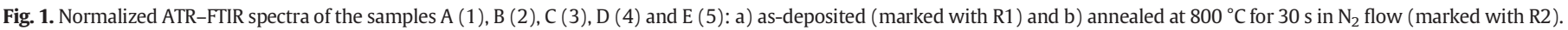


(whatever the deposition approach) are homogeneous and smooth enough $[15,16,18,23]$. For the pure $\mathrm{HfO}_{2}$ layers grown on Si substrate, $\mathrm{SiO}_{2}$ interfacial layers (IL) thinner than $1 \mathrm{~nm}$ were observed. Other layers and structures did not show the formation of such $\mathrm{SiO}_{2}$ IL. Asdeposited samples grown by either RF-MS approach or by combination of RF-MS and PECVD techniques showed similar structural properties. The deposition of top $\mathrm{SiN}_{1.33}$ layer by PECVD (when it was required) did not modify the structure of the underlying layers.

Fig. 3 represents the HR-TEM images of the annealed samples. All the samples show smoothed surface (with the roughness below $1 \mathrm{~nm}$ ) and abrupt interfaces between different stacked layers. No crystallization of Hf-based layers was observed for all structures. This means that neither the formation of grain boundaries in $\mathrm{HfO}_{2}$ layers nor phase separation in $\mathrm{Hf}$ silicate ones occurred upon annealing at $800{ }^{\circ} \mathrm{C}$ during $30 \mathrm{~min}$. Besides, a good interface quality was also observed for the structures produced by combination of RF-MS and PECVD methods (Fig. 2a,b,d) offering good compatibility of both processes for device fabrication.

The formation of $\mathrm{SiO}_{2}$ IL was observed only for the stacks with pure $\mathrm{HfO}_{2}$ layers (sample A, Fig. 2a). The comparison of the stacks with the $\mathrm{SiN}_{0.8}$ layer separating $\mathrm{Hf}$-based layer from $\mathrm{Si}$ substrate in the samples B-R2, C-R2 and D-R2 (Fig. 2b-d) showed that the bottom $\mathrm{SiN}_{0.8}$ layer prevents the development of $\mathrm{SiO}_{2} \mathrm{IL}$ for the structures with pure $\mathrm{HfO}_{2}$ layer (samples B-R2 and C-R2, Fig.2c,d). The comparison of HR-TEM images with corresponding ATR-FTIR spectra allows assuming that the appearance of Si-O vibration band peaked at about $1240 \mathrm{~cm}^{-1}$ is due to either the reconstruction of $\mathrm{Si}-\mathrm{O}$ bonds in Hf silicate layers (sample D$\mathrm{R} 2$ ) or the formation of $\mathrm{Si}-\mathrm{O}$ bonds at $\mathrm{SiN}_{0.8} / \mathrm{HfO}_{2}$ interface (samples B-R2 and C-R2). This fact showed that produced stacked structures will keep their high permittivity after processing that can be used for further vertical scaling of similar structures. The TEM study of the samples E-R2 and F-R2 revealed that their TEM images were very similar to that of sample D-R2 (not shown here).

The samples with $\mathrm{SiN}_{1.33}$ top layer implanted with Ge and submitted to the annealing at $800{ }^{\circ} \mathrm{C}$ ( sample A-Ge3), showed the appearance and crystallization of numerous Ge-ncs (Fig.2a). The position of the formed Ge-ncs is in good agreement with the projected range and width of the low energy implanted profile predicted by TRIDYN for such samples. The Ge diffusion after annealing is limited here due to the low thermal budget used for Ge-ncs nucleation. It is worth to note that no Ge-ncs were observed in the top $\mathrm{SiN}_{0.8}$ layer after such treatment (not shown here).

\subsection{Electrical properties of the structures}

High-frequency (100 kHz-1 MHz) C-V characteristics were measured for all samples. Single sweep measurements were first carried out along the samples. The distance from capacitor to capacitor was about $3 \mathrm{~mm}$ (Fig. 3a-b). In most cases uniform C-V curves were obtained, so indicating a good uniformity in flat-band voltage and equivalent oxide thickness along the samples. No substantial difference in $\mathrm{C}-\mathrm{V}$ data under light and dark conditions was observed.

Comparison of the $\mathrm{C}-\mathrm{V}$ single sweeps for the different structures (Fig.3c) shows that the samples A-R2, C-R2 and D-R2 exhibit sharp $\mathrm{C}-\mathrm{V}$ transition from the depletion to the accumulation regime. At the same time, the $\mathrm{C}-\mathrm{V}$ curves of the samples B-R2, E-R2 or F-R2 suffer from a significant shift towards negative bias values that can be explained by the presence of a high amount of positive charge trapped in the stack.

Forward and backward C-V sweeps were registered for the samples A-R2, D-R2 and B-R2 (Fig. 4), E-R2 and F-R2 (not shown here). Strong
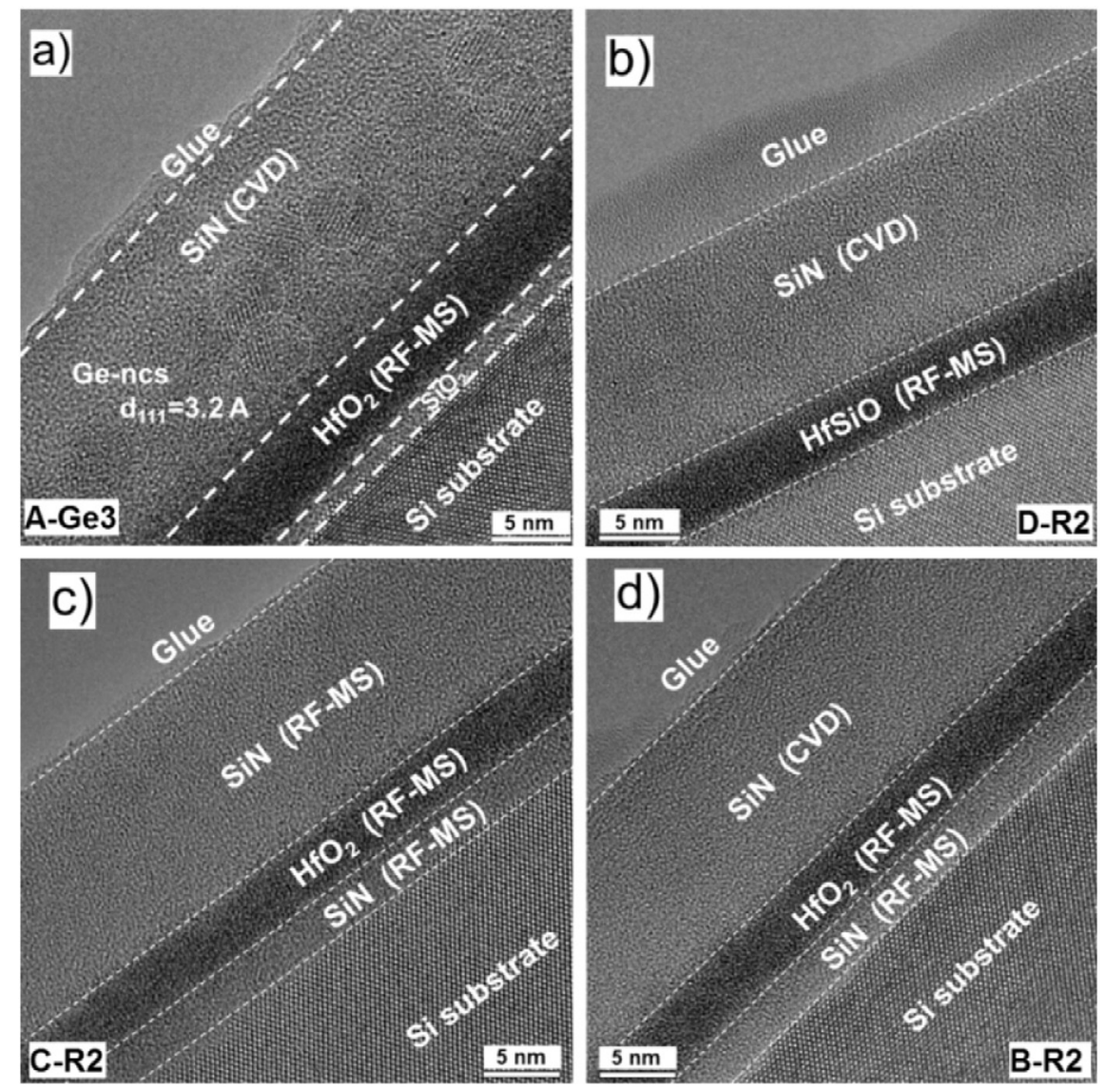

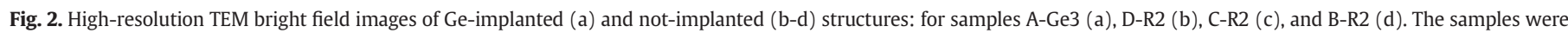
annealed at $800{ }^{\circ} \mathrm{C}$ for 30 min in $\mathrm{N}_{2}$ flow. Top $\mathrm{SiN}_{1.33}$ layer was grown by PECVD (a, b, d) and RF-MS (c) approaches. 

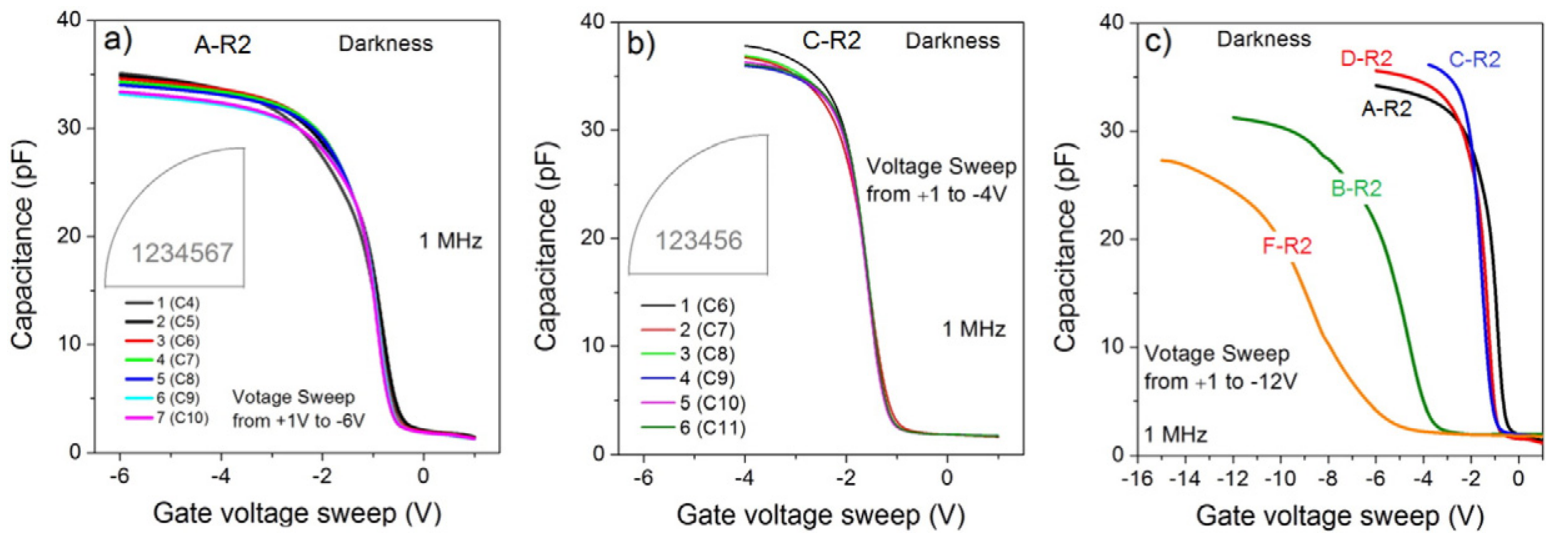

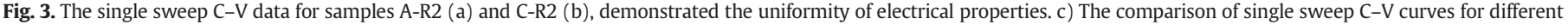
structures mentioned in the figure. All measurements were performed in darkness. The samples were annealed at $800^{\circ} \mathrm{C}$ for 30 min in $\mathrm{N}_{2}$ flow.

hysteresis phenomena were detected for the samples A-R2 (Fig.4a) and D-R2 (Fig.4b). These memory effects, depicted as flat-band voltage shifts in Fig. 4c, relate to both electron and hole injection from the substrate for the sample A-R2, while they are mainly caused by electron injection from the substrate in the case of the sample D-R2; a trait indicating a larger energy barrier for hole injection for the latter sample compared to the former. The charging effect was found to be uniform from capacitor to capacitor under light conditions. Only slight variations in the injection efficiency of minority carriers (electrons) were found under dark conditions.
Preliminary charge retention measurements have been performed at room temperature after application of $\mathrm{a}+6 \mathrm{~V}$ gate voltage stress for 10 s. Two charge-loss regimes were observed. A regime where a significant part of the injected charge ( $30 \%$ for sample D-R2 and $60 \%$ for sample A-R2) is rapidly lost within the first $100 \mathrm{~s}$, and a second regime during which the flat-band voltage shift decreases linearly with the logarithm of the waiting time (see Fig. 4d). From the logarithmic time dependence of the charge loss, flat-band voltage shifts of about 0.2 (D-R2) and $0.1 \mathrm{~V}(\mathrm{~A}-\mathrm{R} 2)$ are estimated for a 10 -year waiting time. The two above regimes suggest two different charge-loss processes but more
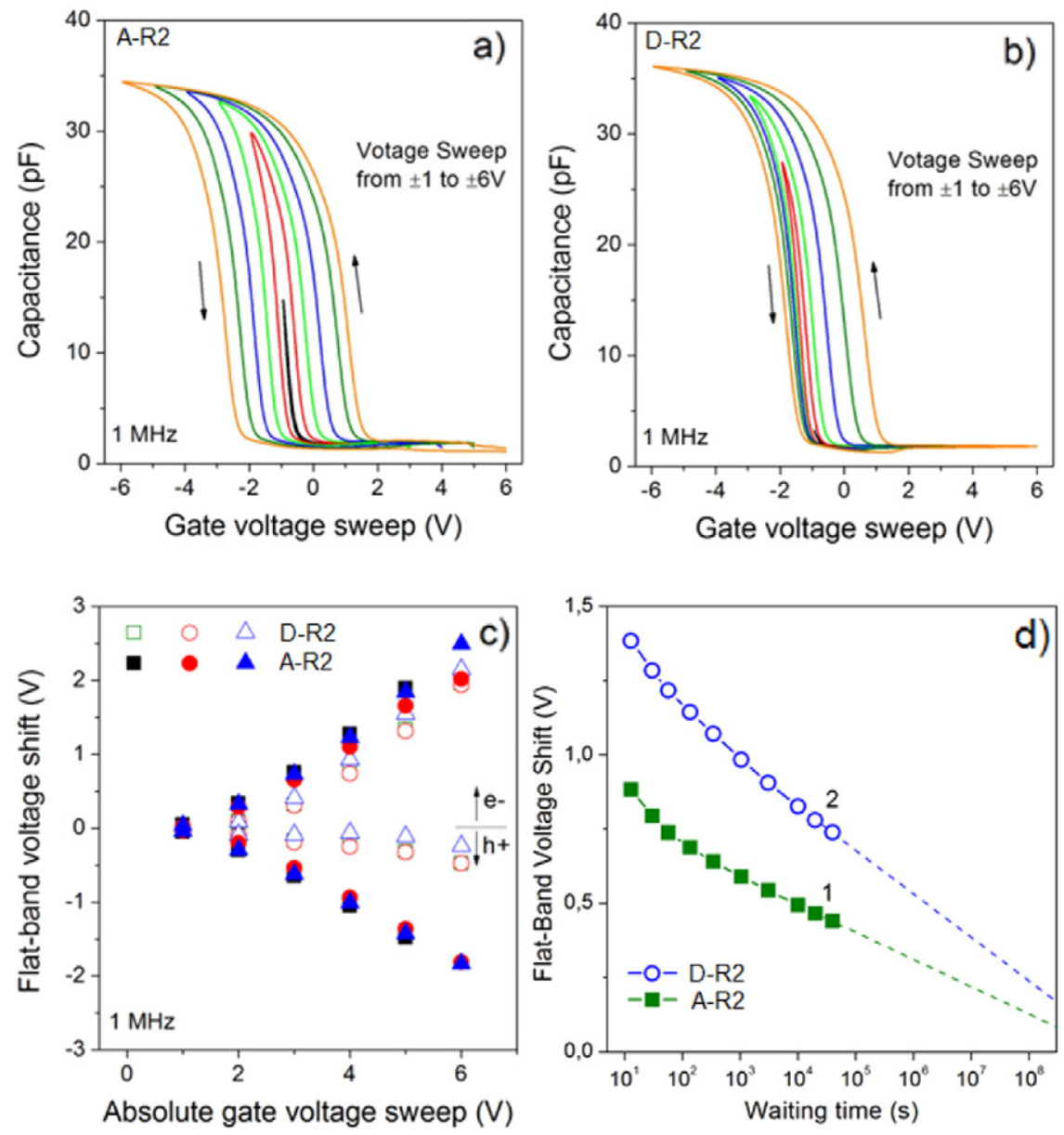

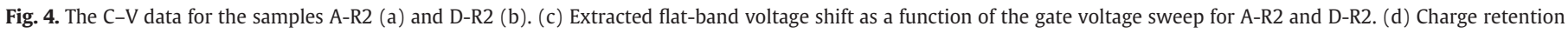

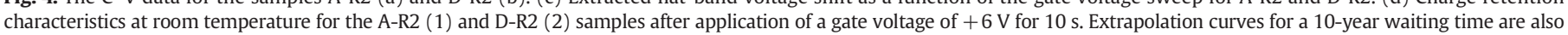
reported. The samples were annealed at $800{ }^{\circ} \mathrm{C}$ for $30 \mathrm{~min}$ in $\mathrm{N}_{2}$ flow. The measurements were performed in darkness. 

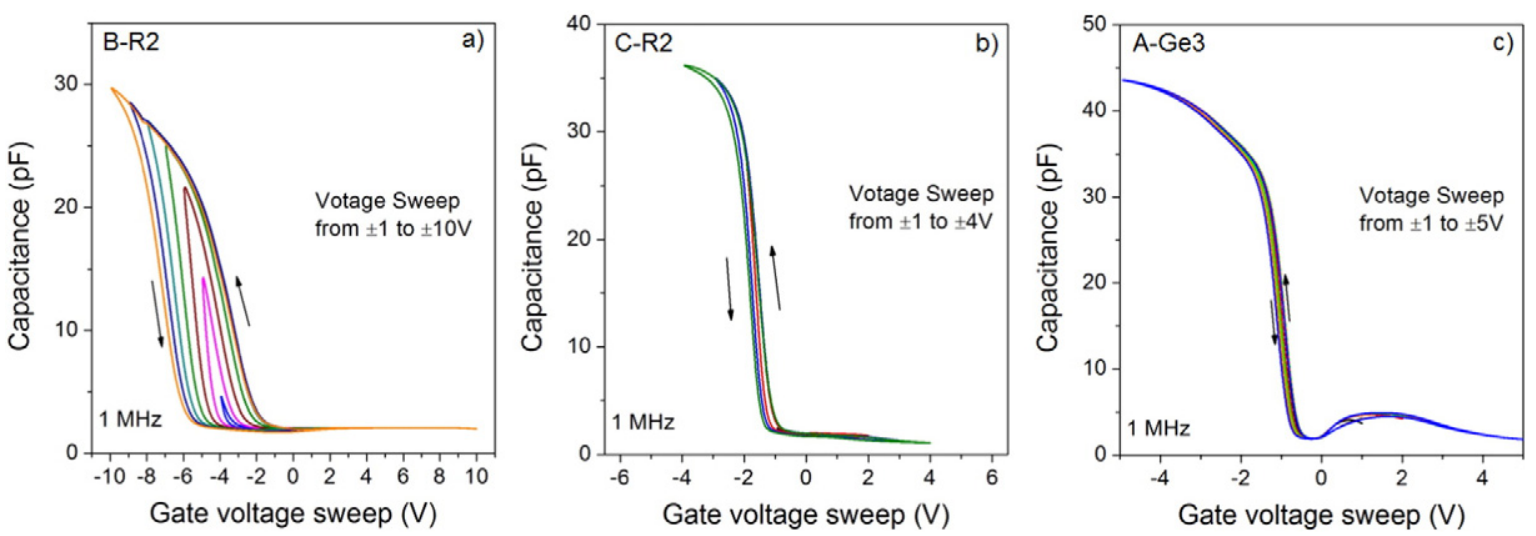

Fig. 5. The C-V data for the samples C-R2 (a), B-R2 (b) and A-Ge3 (c). The samples were annealed at $800{ }^{\circ} \mathrm{C}$ for 30 min in $\mathrm{N}_{2}$ flow. The measurements were performed in darkness.

investigations are needed to draw safe conclusions on the leakage paths and the nature of the associated mechanisms.

C-V hysteresis was also observed for the sample B-R2 (Fig.5a), whereas no (or negligible) charge trapping was detected for the sample C-R2 (Fig.5b). These two samples differ in the stoichiometry of the top $\mathrm{Si}$ nitride layer. Stoichiometric $\mathrm{SiN}_{1.33}$ (former case) is known to demonstrate good charge trapping characteristics $[2,3,32,36]$. Thus, one can assume that for the structures with top $\mathrm{SiN}_{1.33}$ layer, the latter can contribute significantly to the hysteresis effect. Besides, Hf-silicate layer can also participate to charge trapping as it was shown earlier [17]. It is worth to note that the triple stacked samples demonstrated also good reproducibility in $\mathrm{C}-\mathrm{V}$ characteristics from capacitor to capacitor.

C-V measurements of the samples implanted with Ge and submitted to annealing at $800{ }^{\circ} \mathrm{C}$ (see Fig.5c) revealed the vanishing of the strong hysteresis phenomenon previously reported for the non-Ge-implanted sample (Fig.4a). Similar C-V data were obtained for most samples with embedded Ge-ncs. The comparison of their structural and electrical properties (Figs. 3-5) allowed the assumption that the lateral and vertical spatial distribution of Ge-ncs can be responsible for the disappearance of the memory effects. However, this effect requires further investigations and additional studies are ongoing to draw safe conclusions regarding the location and the retention time of the trapped charge.

\section{Conclusions}

Stacked dielectrics were fabricated by combination of RF magnetron sputtering and PECVD approaches. All the stacked samples demonstrate good interface and surface roughness quality after thermal treatment at $800{ }^{\circ} \mathrm{C}$ for $30 \mathrm{~min}$ in $\mathrm{N}_{2}$ flow. Amorphous nature and stable phase composition were observed for pure $\mathrm{HfO}_{2}$ and $\mathrm{Hf}$ silicate layers after annealing. Significant charging effects caused by carriers' injection from the substrate and further trapping were observed for the stacks with a top Si nitride layer grown by PECVD. No substantial memory phenomenon was observed when Ge nanocrystals were formed in the top Si nitride layer. Such a concern may be related to the spatial distribution of the Ge nanocrystals within the dielectric stacks but more research is needed to confirm this point.

\section{Acknowledgment}

The research leading to these results has received funding from the French National Research Agency (ANR) through the Nanoscience and Nanotechnology Program (NOMAD project no. ANR-07-NANO-022-02), the Conseil Régional de Basse Normandie through the CPER project Nanoscience axe (2007-2013), the Programme Investissements d'Avenir under the program ANR-11-IDEX-0002-02, reference ANR-10-LABX0037-NEXT (grant for invited researchers, the European Union Seventh
Framework Program under Grant Agreement 312483-ESTEEM2 (Integrated Infrastructure Initiative-I3), as well as bilateral UkrainianFrench program DNIPRO (2015-2016 edition) (project no. 34820QH and no. M/115-2015).

\section{References}

[1] S. Gerardin, A. Paccagnella, Present and future non-volatile memories for space, IEEE Trans. Nucl. Sci. 57 (2010) 3016-3039.

[2] M.L. French, C.Y. Chen, H. Sathianathan, M.H. White, Design and scaling of a SONOS multidielectric device for nonvolatile memory applications, IEEE Trans. Compon. Packag. Manuf. Technol. Part A 17 (1994) 390-397.

[3] X. Wang, J. Liu, W. Bai, D.L. Kwong, A novel MONOS-type nonvolatile memory using high-к dielectrics for improved data retention and programming speed, IEEE Trans. Electron Devices 51 (2004) 597-602.

[4] M.S. Joo, B.J. Cho, C.C. Yeo, D.S.H. Chan, S.J. Whoang, S. Matthew, L.K. Bera, N. Bala, D.L. Kwong, Formation of hafnium-aluminum-oxide gate dielectric using single cocktail liquid source in MOCVD process, IEEE Trans. Electron Devices 50 (2003) 2088-2094.

[5] H.-K. Fang, K.-S. Chang-Liao, C.-Y. Chen, H.-W. Ho, Effects of $\mathrm{HfO}_{2} / \mathrm{SiON} / \mathrm{SiN}$ stacked trapping layer on operation characteristics of poly-Si flash memory devices, Microelectron. Eng. 138 (2015) 107-110.

[6] H.K. Kim, I.-H. Yu, J.H. Lee, Ch.S. Hwang, Interfacial dead-layer effects in Hf-silicate films with Pt or $\mathrm{RuO}_{2}$ gates, ACS Appl. Mater. Interfaces 5 (2013) 6769-6772.

[7] R. Chau, S. Datta, M. Doczy, B. Doyle, J. Kavalieros, M. Metz, High-k/metal-gate stack and its MOSFET characteristics, IEEE Electron Device Lett. 25 (2004) 408-410.

[8] M.S. Kim, Y.D. Ko, M. Yun, J.H. Hong, M.C. Jeong, J.M. Myoung, I. Yun, Characterization and process effects of $\mathrm{HfO}_{2}$ thin films grown by metal-organic molecular beam epitaxy, Mater. Sci. Eng. B 123 (2005) 20-30.

[9] A.C. Jones, P.R. Chalker, Some recent developments in the chemical vapour deposition of electroceramic oxides, J. Phys. D. Appl. Phys. 36 (2003) R80-R95.

[10] M. Lemberger, A. Paskaleva, S. Zürcher, A.J. Bauer, L. Frey, H. Ryssel, Electrical properties of hafnium silicate films obtained from a single-source MOCVD precursor, Microelectron. Reliab. 45 (2005) 819-822.

[11] T. Nishide, S. Honda, M. Matsuura, M. Ide, Surface, structural and optical properties of sol-gel derived $\mathrm{HfO}_{2}$ films, Thin Solid Films 371 (2000) 61-65.

[12] M.G. Blanchin, B. Canut, Y. Lambert, V.S. Teodorescu, A. Barau, M. Zaharescu, Structure and dielectric properties of $\mathrm{HfO}_{2}$ films prepared by a sol-gel route, J. Sol-Gel Sci. Technol. 47 (2008) 165-172.

[13] H. Hu, C.X. Zhu, Y.F. Lu, Y.H. Wu, T. Liew, M.F. Li, B.J. Cho, W.K. Choi, N. Yakovlev, Physical and electrical characterization of $\mathrm{HfO}_{2}$ metal-insulator-metal capacitors for Si analog circuit applications, J. Appl. Phys. 94 (2003) 551-557.

[14] S.S. Hullavarad, D.E. Pugel, E.B. Jones, R.D. Vispute, T. Venkatesan, Low leakage current transport and high breakdown strength of pulsed laser deposited $\mathrm{HfO}_{2} / \mathrm{SiC}$ metal-insulator-semiconductor device structures, J. Electron. Mater. 36 (2007) 648-653.

[15] L. Khomenkova, C. Dufour, P.-E. Coulon, C. Bonafos, F. Gourbilleau, High-k Hf-based layers grown by RF magnetron sputtering, Nanotechnology 21 (2010) 095704.

[16] L. Khomenkova, X. Portier, J. Cardin, F. Gourbilleau, Thermal stability of high-k Sirich $\mathrm{HfO}_{2}$ layers grown by RF magnetron sputtering, Nanotechnology 21 (2010) 285707.

[17] L. Khomenkova, X. Portier, A. Slaoui, F. Gourbilleau, Charge trapping in hafnium silicate films with modulated composition and enhanced permittivity, Adv. Mater. Res. 854 (2014) 125-133.

[18] E. Talbot, M. Roussel, L. Khomenkova, F. Gourbilleau, P. Pareige, Atomic scale microstructures of high-k HfSiO thin films fabricated by magnetron sputtering, Mater. Sci. Eng. B 177 (2012) 717-720.

[19] D. Khomenkov, Y.-T. An, X. Portier, C. Labbe, F. Gourbilleau, L. Khomenkova, Lightemitting and structural properties of Si-rich $\mathrm{HfO}_{2}$ thin films fabricated by RF magnetron sputtering, MRS Proc. 1617 (2013) 85-91. 
[20] L. Khomenkova, M. Baran, O. Kolomys, V. Strelchuk, A.V. Kuchuk, V.P. Kladko, J. Jedrzejewski, I. Balberg, Y. Goldstein, P. Marie, F. Gourbilleau, N. Korsunska, Comparative investigation of structural and optical properties of Si-rich oxide films fabricated by magnetron sputtering, Adv. Mater. Res. 854 (2014) 117-124.

[21] L. Khomenkova, X. Portier, M. Carrada, C. Bonafos, B.S. Sahu, A. Slaoui, F. Gourbilleau, Ge-doped Hafnia-based dielectrics for non-volatile memory applications, ECS Trans. 45 (2012) 331-339.

[22] D. Lehninger, L Khomenkova, C Röder, G Gärtner, B. Abendroth, J. Beyer, F. Schneider, D.C. Meyer, J. Heitmann, Ge Nanostructures embedded in $\mathrm{ZrO}_{2}$ dielectric films for nonvolatile memory applications, ECS Trans. 66 (2015) 203-212.

23] B.S. Sahu, F. Gloux, A. Slaoui, M. Carrada, D. Muller, J. Groenen, C. Bonafos, S. Lhostis, Effect of ion implantation energy for the synthesis of Ge nanocrystals in SiN films with $\mathrm{HfO}_{2} / \mathrm{SiO}_{2}$ stack tunnel dielectrics for memory application, Nanoscale Res. Lett. 6 (2011) 177.

[24] J.H. Choi, Y. Mao, J.P. Chang, Development of hafnium based high-k materials - a review, Mater. Sci. Eng. R 72 (2011) 97-136.

[25] J.P. Maria, D. Wicaksana, A.I. Kingon, B. Busch, H. Schulte, E. Garfunkel, T. Gustafsson, High temperature stability in lanthanum and zirconia-based gate dielectrics, J. Appl Phys. 90 (2001) 3476-3482.

[26] M. Toledano-Luque, M.L. Lucía, A. del Prado, E. San Andrés, I. Mártil, G. GonzálezDíaz, Appl. Phys. Lett. 91 (2007) 191502

[27] L.-P. Feng, Z.-T. Liu, Q.-J. Liu, H. Tian, IOP Conf. Ser.: Mater. Sci. Eng. 12 (2010) 012013.
[28] D.A. Neumayer, E. Cartier, Materials characterization of $\mathrm{ZrO}_{2}-\mathrm{SiO}_{2}$ and $\mathrm{HfO}_{2}-\mathrm{SiO}_{2}$ binary oxides deposited by chemical solution deposition, J. Appl. Phys. 90 (2001) 1801-1808.

[29] C.T. Kirk, Quantitative analysis of the effect of disorder-induced mode coupling on infrared absorption in silica, Phys. Rev. B 38 (1988) 1255-1273.

[30] P. Lange, Evidence for disorder-induced vibrational mode coupling in thin amorphous $\mathrm{SiO}_{2}$ films, J. Appl. Phys. 66 (1989) 201-204

[31] H. Ono, T. Ikarashi, K. Ando, T. Kitano, Infrared studies of transition layers at $\mathrm{SiO}_{2} / \mathrm{Si}$ interface, J. Appl. Phys. 84 (1998) 6064-6069.

[32] H. García, S. Dueñas, H. Castán, A. Gómez, L. Bailón, M. Toledano-Luque, A. del Prado, I. Mártil, G. González-Díaz, J. Appl. Phys. 104 (2008) 094107.

[33] N.V. Nguyen, A.V. Davydov, D. Chandler-Horowitz, M.F. Frank, Sub-bandgap defect states in polycrystalline hafnium oxide and their suppression by admixture of silicon, Appl. Phys. Lett. 87 (2005) 192903.

[34] G. Lucovsky, J. Lüning, N.A. Stoute, H. Seo, C.L. Hinkle, B. Ju, Band edge traps at spectroscopically-detected O-atom vacancies in nanocrystalline $\mathrm{ZrO}_{2}$ and $\mathrm{HfO}_{2}$ : an engineering solution for elimination of $\mathrm{O}$-atom vacancy defects in non-crystalline ternary silicate alloys, ECS Trans. 1 (5) (2006) 381-392.

[35] K.-Ch. Lin, S.-Ch. Lee, The structural and optical properties of a-SiN $\mathrm{x}: \mathrm{H}$ prepared by plasma-enhanced chemical-vapor deposition, J. Appl. Phys. 72 (1992) 5474-5482.

[36] O. Debieu, R. Pratibha Nalini, J. Cardin, X. Portier, J. Perrière, F. Gourbilleau, Structural and optical characterization of pure Si-rich nitride thin films, Nanoscale Res. Lett. 8 (2013) 31. 